\title{
Strength and Deformability of Fiber Reinforced Cement Paste on the Basis of Basalt Fiber
}

\author{
Yury Barabanshchikov and Ilya Gutskalov \\ Peter the Great St. Petersburg Polytechnic University, Polytechnicheskaya 29, St. Petersburg 195251, Russia \\ Correspondence should be addressed to Yury Barabanshchikov; barabanshchikov.yury.47@mail.ru
}

Received 30 November 2015; Revised 27 April 2016; Accepted 23 May 2016

Academic Editor: Arnaud Perrot

Copyright (C) 2016 Y. Barabanshchikov and I. Gutskalov. This is an open access article distributed under the Creative Commons Attribution License, which permits unrestricted use, distribution, and reproduction in any medium, provided the original work is properly cited.

\begin{abstract}
The research object of the paper is cement paste with the particulate reinforcement of basalt fiber. Regardless of fibers' length at the same fiber cement mix workability and cement consumption equality compressive solidity of the specimens is reduced with increasing fiber content. This is due to the necessity to increase the water-cement ratio to obtain a given workability. The flexural stability of the specimens with increasing fiber content increments in the same conditions. There is an optimum value of the fibers' dosage. That is why stability has a maximum when crooking. The basaltic fiber particulate reinforcement usage can abruptly increase the cement paste level limiting extensibility, which is extremely important in terms of crack resistance.
\end{abstract}

\section{Introduction}

Industrial application of fiber reinforced cement composites is one of the concrete industry and research activity important issues [1]. Nowadays, much attention is paid to the powder concretes with special properties [2-6]. Coarse aggregate absence in such concretes does not require long fibers use and thus creates the prerequisites for obtaining high-tech fiber-concrete mixtures [7]. There are many types of the fiber with different materials and geometric properties. Basalt fiber differs from the steel fiber by less weight and much less thermal conduction. They are differed from asbestos fibers by environmental safety. Basalt fiber is cheaper than glass fiber, because it does not require the fabrication of raw materials multicomponent blend and has a large database in the form of common rocks solids [8]. Basalt fiber can successfully compete with synthetic fibers, giving to the concrete improved crack resistance, stability, and stiffness [9]. Concrete stability increase is connected not only with reinforcing effect, but also with high cohesion of cement stone and basalt fiber that is a positive difference from the other types of fibers [10]. The fact that chopped basalt fiber in concrete can delay the early stability of concrete is demonstrated in the current work [11]. In this context, the compressive strength reached a peak value with $0.1 \%$ (by volume) fiber dosage. Current work results point out that the highest flexural and compressive flexibility of reactive powder concrete (RPC) can be obtained when the fiber content is $3 \mathrm{~kg} / \mathrm{m}^{3}$, which also constitutes about $0.1 \%$ by volume [12]. Basalt fiber replenishment significantly improves the tensile strength and flexural strength, whereas the compressive strength shows no obvious increase. The fiber length increase from 12 to $22 \mathrm{~mm}$ has led to an increase in tensile stability and bending only fractions of a percent [13]. Inclusion of basalt fiber in concrete resulted in decreasing of the compressive strength [14]. However, test results showed that an improved bending strength, fracture energy, and abrasion resistance can be obtained by using basalt fiber even at low contents. Chopped basalt fibers increase the flexural strength while the steel and polyvinyl alcohol fibers show losses in the results per mixes [15]. All types of fiber impregnation caused an increase in water demand to achieve the required workability and a small reduction (10 to 15\%) in compressive strength. When the concrete contains basalt fiber, the compression strength of it is unstable, the tensile strength increases with fiber content, and durability and impact resistance increase considerably [16]. Also basalt fiber has little effect on compressive strength of the fiber reinforced concrete but significantly increases its toughness [17]. The difference of ultimate strength and strain between basalt-fibers-specimens and glass-fibers-specimens 


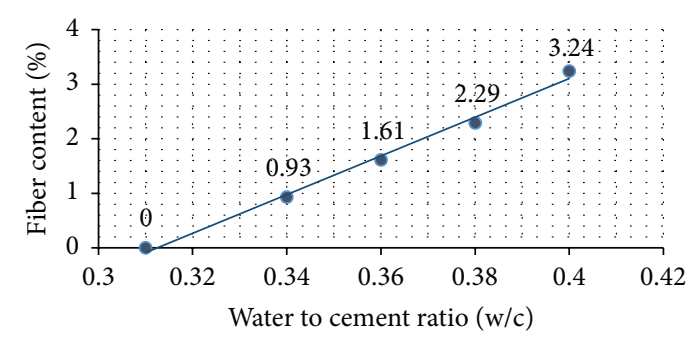

Figure 1: The fiber content versus water to cement ratio relation.

is insignificant based on maximum and mean values at 1 or 7 days. For glass-fibers-specimens, the averaged 28-day ultimate strain is $8-9 \%$ lower than those 7 -day ones possibly due to rapid setting cement use and slightly decreasing pullout behavior. In basalt-fibers-specimens, the higher drops in averaged ultimate strengths (15\%) and strains (27\%) are noted at 28 days [18].

The purpose of this work is studying the influence of particulate reinforcement of basaltic fiber for solidity and deformability of fiber reinforced cement composite depending on the fiber length and its dosage.

\section{Specimens Making}

The following are used for the making of specimens: Portland cement CEM I 42.5R production of JSC "Mordovcement" and two types of the basalt fiber with identical diameter $16 \mathrm{mcm}$ and different length of $12.7 \mathrm{~mm}$ (1B) and $24.5 \mathrm{~mm}(2 \mathrm{~B})$.

Traditional technique with stirring paddle mixer was used to get the fiber reinforced cement mix. Fiber (1B) was injected into the prepared mixture during mixing. Fiber (2B) was added to the dry mixture, mixed, and injected with water. Fiber cement mixtures with equal mobility were selected to make these tests happen. In addition to this, specimens with the sizes of $40 \times 40 \times 160 \mathrm{~mm}$ which had been stored under normal conditions and tested for bend and compression were prepared.

The details of the mix proportions are provided in Table 1.

Table 1 shows that the water-cement ratio in tested compositions of fiber cement increases with the rising of the fiber content. This is due to the necessity of increasing the water-cement ratio to obtain a given workability as a fiber increases the level of water demand of the mixture. Curve "fiber content versus water content" is shown in Figure 1. Therefore, the test results are dependent both on two factors: fiber content and water-cement ratio.

\section{The Results of Testing Fiber Cement Specimens}

Results of flexural strength and compressive strength from compositions of fiber reinforced cement are shown in Figure 2 and presented in graphs. Flexural and compressive strength of specimens with length of fibers $12.7 \mathrm{~mm}$ depend on two factors: fiber's content by volume and water to cement ratio $(w / c)$.

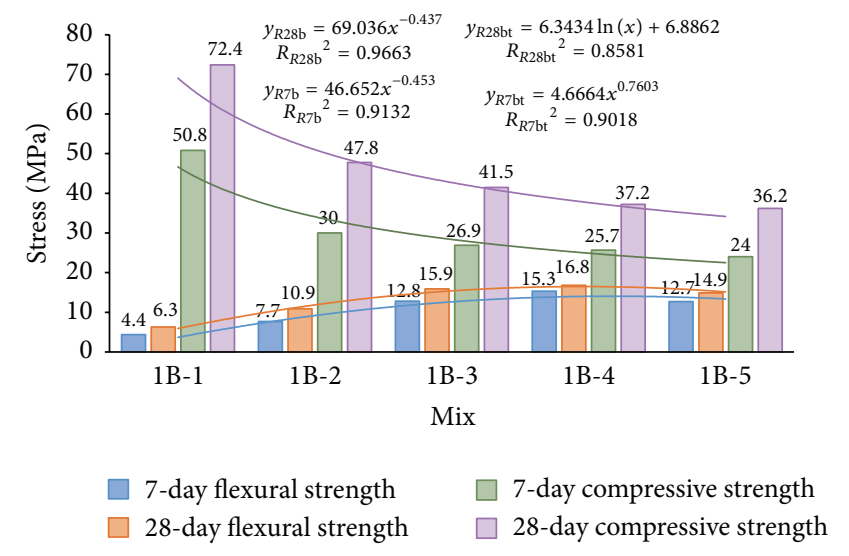

Figure 2: Flexural strength and compressive strength of 1Bspecimens.

Graphs in Figure 2 show how content of the fibers and water to cement ratio $(\mathrm{w} / \mathrm{c})$ influence differently the flexural strength and compressive strength. It has become a common knowledge that the concrete compressive strength reduced with the water towards cement ratio usual growth w/c. Flexural strength was incremented with water to cement ratio $(w / c)$. However, in our case, with the increase of water to cement ratio $(\mathrm{w} / \mathrm{c})$ fiber reinforced cement flexural stability did not fall but even increased.

Obviously, the content of reinforcing fibers is the main factor influencing the flexural strength. Fibers have high tensile strength and overlap of the strength reduction caused by increasing of the water to cement ratio $(\mathrm{w} / \mathrm{c})$. If proportion of fibers rise up to $2.29 \%$ (by volume) flexural strength of specimens firstly increases and then slowly decreases. Increasing the amount of fiber content leads to a rising surface area of jamming with the concrete. Also, a large number of reinforcing fibers prevent the action of the bending force.

Basalt fibers are not subject to an alkaline resistance in the process of maturing of composite. This reinforcing filling does not absorb ions $\mathrm{Ca}^{2+}$ in the hydration and hydrolysis reactions. Therefore, basalt fiber retains the initial strength in the hardened state of concrete.

Simultaneously, reducing the compressive strength gives a regular dependence on the water to cement ratio $(\mathrm{w} / \mathrm{c})$. It is quite clear that the flexible fibers are not able to perceive the compressive forces and do not affect the compressive strength. The ratio of the compressive strength to flexural strength in bending for optimal composition $1 \mathrm{~B}-4$ equals $R_{\mathrm{b}} / R_{\mathrm{bt}}=1.7$ for the 7-day fiber cement and 2.2 for 28 day fiber reinforced cement. In the absence of fiber (control composition of specimens $1 \mathrm{~B}-1$ ), the ratio is 11.5 , which corresponds to the normal values for concrete being 10-20.

Figure 3 demonstrates the graphs of fiber reinforced cement on flexural and compressive strength from content of reinforcing fibers 1B. Strength of specimens with length of fibers $24.5 \mathrm{~mm}$ depends on two factors: fiber's content by volume and water to cement ratio $(\mathrm{w} / \mathrm{c})$. These factors compete against themselves. Content of reinforcing fibers is dominating factor affecting the flexural strength. Watercement ratio is dominating factor affecting the compressive 
TABLE 1: The compositions of specimens on the basis of basalt fiber.

\begin{tabular}{|c|c|c|c|c|c|}
\hline \multirow{2}{*}{ Material consumption mixture } & \multicolumn{5}{|c|}{ The compositions of fiber reinforced cement } \\
\hline & $1 \mathrm{~B}-1$ and $2 \mathrm{~B}-1$ & $1 \mathrm{~B}-2$ and $2 \mathrm{~B}-2$ & $1 \mathrm{~B}-3$ and $2 \mathrm{~B}-3$ & $1 \mathrm{~B}-4$ and $2 \mathrm{~B}-4$ & $1 \mathrm{~B}-5$ and $2 \mathrm{~B}-5$ \\
\hline Cement, $\mathrm{kg} / \mathrm{m}^{3}$ & 1565 & 1481 & 1426 & 1377 & 1326 \\
\hline Water, $\mathrm{kg} / \mathrm{m}^{3}$ & 485 & 503 & 514 & 523 & 530 \\
\hline Fiber, $\mathrm{kg} / \mathrm{m}^{3}$ & - & 26,9 & 47,6 & 66,4 & 94 \\
\hline Content of fiber, $\%$ & - & 0,93 & 1,61 & 2,29 & 3,24 \\
\hline Water to cement ratio $(\mathrm{w} / \mathrm{c})$ & 0,31 & 0,34 & 0,36 & 0,38 & 0,40 \\
\hline
\end{tabular}

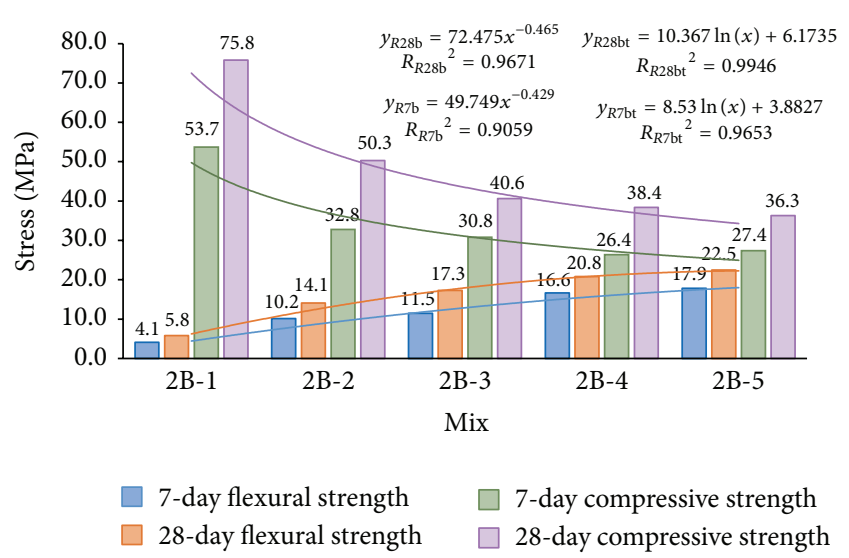

Figure 3: Flexural strength and compressive strength of 2Bspecimens.

strength. Flexural strength increases with incrementing of fiber content. However, unlike the previous occasion, value compressive strength did not amount to maximum. Compressive strength is reduced accordingly with rising the watercement ratio $(\mathrm{W} / \mathrm{C})$, but it does not depend on increasing content of the fibers. The ratio of the compressive strength to flexural strength in bending for fiber reinforced cement with the highest fiber content equals $R_{\mathrm{b}} / R_{\mathrm{bt}}=1.5$ for the 7 -day fiber cement and 1.6 for 28 -day fiber reinforced cement. This relation equals 13.1 in the absence of fiber (check composition $2 \mathrm{~B}-5)$. This rate to the normal values for concrete is 10-20.

Comparison of the flexural strength and the compressive strength of fiber reinforced cement on the fiber types $1 \mathrm{~B}$ and $2 \mathrm{~B}$ discloses that flexural strength rises on $17-30 \%$ on an average during increasing length of the fibers. But this factor does not influence compressive strength.

The results of dependence of deformation properties mechanical strength of specimens with the sizes of $40 \times 40 \times$ $160 \mathrm{~mm}$ on length of basalt fiber are shown in Figures 4 and 5 . Deformation during the loading was measured by using the strain-gauge, which is glued to the surface of the face of the sample.

These results describe the crack resistance of concrete. From this standpoint, evaluate the limit extensibility of the concrete which is the maximum value to the relative flexural strain up to disruption continuity of composite. Flexural strain of fiber cement and deformation properties of compositions 1B-fibers are shown in Figure 4.

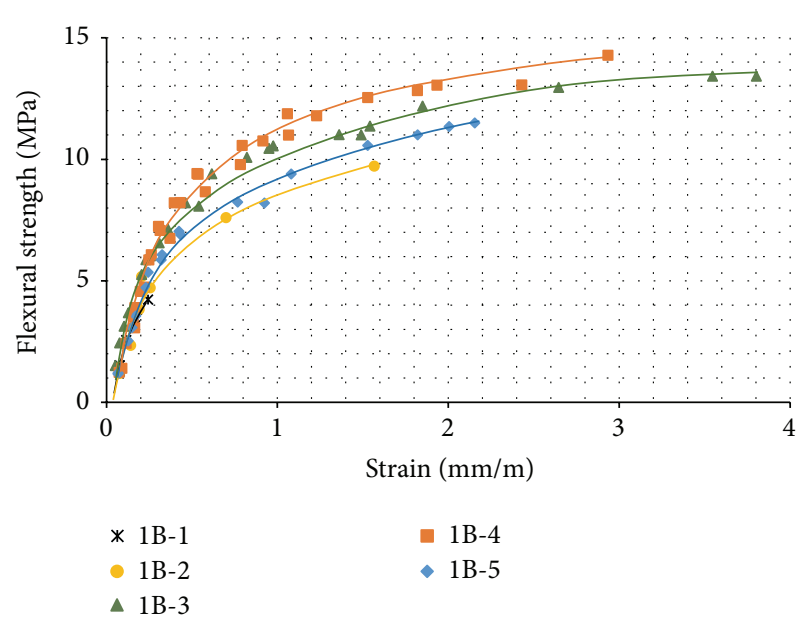

Figure 4: Curves "flexural strength-strain” of 1B-specimens.

Maximal value of flexural strain of $3.8 \mathrm{~mm} / \mathrm{m}$ amounts to the composition 1B-3 at content of the fibers, which equals $1.6 \%$. Composition 1B-4 has the largest flexural strength that conforms $2.3 \%$ of reinforcing filling. This maximal value is $2.93 \mathrm{~mm} / \mathrm{m}$, but it is below that in the previous case. The remaining compositions of decreasing order of maximal values of flexural strain are located according to the decrease content of fibers. Control composition 1B-1 showed the minimal value of the flexural capacity, $0.25 \mathrm{~mm} / \mathrm{m}$. So, enlargement of reinforcing fibers condition increases maximum tensile strain up to fracture. However, there is an optimum value content of the fiber, which gives the maximal magnitude of flexural strain. In our case, this content of $1 \mathrm{~B}-$ fibers is $1.6 \%$.

Results of flexural strain for 2B-specimens as curves "flexural strength-strain" are shown in Figure 5.

Comparison of curves in Figures 4 and 5 demonstrates that compositions $2 \mathrm{~B}$ have flexural strength-strain more than compositions 1B. The cause of this is increasing length of fibers and rising length of its anchoring in cement paste. After the appearance of cracks in specimens from the load, fibers start to perceive bending loads. Some fibers are torn but some pulled out. This can be explained as more strain capacity in 2B-specimens with the highest of fiber length than 1B-specimens. In both cases, increasing of the fiber content in the fiber reinforced cement mixture leads to an increment of bending strength and compressive strength, 


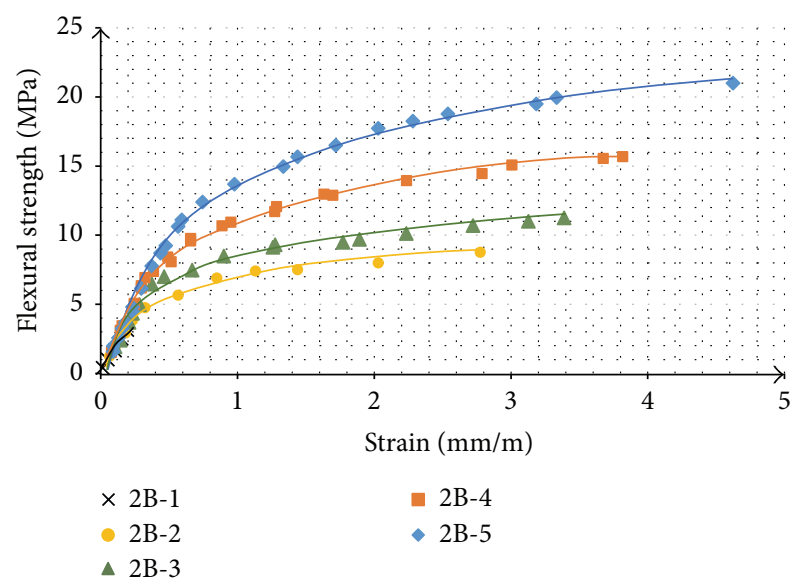

Figure 5: Curves “flexural strength-strain” of 2B-specimens.

but there is a maximum of these properties after which the reduction of indicators in the fiber increasing dosage begins. This maximum value was obtained on a short fiber with its content of about $1.6 \%$. This value is optimal tensile strength and flexural strain. In the case of $2 \mathrm{~B}$-fibers optimal content was not obtained. Probably it is above the values used in the experiments of dosage of basalt fiber.

\section{Conclusion}

Regardless of the fibers' length at the same mobility of concrete and cement consumption equality the strength of concrete in compression decreases with increase in fiber content, which is associated with the necessity of increasing of the water-cement ratio to obtain the given mobility.

Under the same conditions, a flexural strength of concrete with fiber content enlargement rises to a certain value corresponding to the optimal content of the fiber, and the flexural strength decreases equally with a further fibers amount increase. The fibers length growth also has a positive effect on the flexural strength. The optimum content of the reinforcing fibers depends on their length, as well as the composition of the concrete.

The dominant factor influencing the flexural strength of the reinforcing fiber content is providing a high tensile strength and a decrease in strength of equitant caused by increasing of the water to the cement ratio $(\mathrm{w} / \mathrm{c})$. The dominant factor influencing the compressive strength is water to cement ratio $(\mathrm{w} / \mathrm{c})$ because the flexible fibers are not able to take compressive loads.

The basaltic fiber particulate reinforcement usage can dramatically increase the cement paste stretch level, which is extremely important in terms of crack resistance. Together with the fiber length growth, concrete fiber tensibility limit rises. The fiber content in the fiber cement mixture extension leads to the tensile strain gain, but there is a limit of tensibility over which these indicators jointly with the fiber dosage swelling start to decline. This maximum was obtained at the fiber with length of $12.7 \mathrm{~mm}$ at its content being about $1.6 \%$. This value is optimal flexural strength and strain.

\section{Competing Interests}

The authors declare that they have no competing interests.

\section{References}

[1] O. Holčapek, P. Reiterman, and P. Konvalinka, "Experimental investigation of hydrothermal curing influence on mechanical properties of fiber-cement composite," in Proceedings of the 52nd International Conference on Experimental Stress Analysis (EAN '14), Code 107000, Mariánské Lázně, Czech Republic, June 2014.

[2] A. A. Shishkin, "Shchelochnyye reaktsionnyye poroshkovyye betony (Alkaline reaction powder concretes)," Construction of Unique Buildings and Structures, vol. 2, no. 17, pp. 56-65, 2014 (Russian).

[3] A. A. Shishkina, "The porous reactive powder concrete," Construction of Unique Buildings and Structures, vol. 8, no. 23, pp. 128-135, 2014 (Russian).

[4] A. Shishkin, A. Shishkina, and N. Vatin, "Low-shrinkage alcohol cement concrete," Applied Mechanics and Materials, vol. 633-634, pp. 917-921, 2014.

[5] V. Korsun, N. Vatin, A. Korsun, and D. Nemova, "Physicalmechanical properties of the modified fine-grained concrete subjected to thermal effects up to $200^{\circ} \mathrm{C}$," Applied Mechanics and Materials, vol. 633-634, pp. 1013-1017, 2014.

[6] A. Ponomarev, M. Knezević, N. Vatin, S. Kiski, and I. Ageev, "Nanosize scale additives mix influence on the properties of the high performance concretes," Journal of Applied Engineering Science, vol. 12, no. 3, pp. 227-231, 2014.

[7] S. V. Klyuyev, "Vysokoprochnyy fibrobeton dlya promyshlennogo i grazhdanskogo stroitel'stva (High-strength fiber concrete for industrial and civil construction)," Magazine of Civil Engineering, vol. 8, pp. 61-66, 2012 (Russian).

[8] Y. V. Pukharenko, "Principles of forming the structures and prediction of fibrous concrete strength," Stroitel'nye Materialy, no. 10, pp. 47-50, 2004.

[9] Y. V. Pukharenko, "Strength and durability of cellular fibrous concrete," Stroitel'nye Materialy, no. 12, pp. 40-42, 2004.

[10] F. N. Rabinovich, Composites Based on Fibre Concretes. The Issue of the Theory and Design, Technology, Construction, ASV, Moscow, Russia, 2011 (Russian).

[11] Y. Barabanshchikov, S. Belyaeva, A. Avdeeva, and M. Perez, "Fiberglass reinforcement for concrete," Applied Mechanics and Materials, vol. 725-726, pp. 475-480, 2015.

[12] Y. Barabanshchikov, A. Turkebayev, A. Dalabayev, and D. Tleukhanov, "Influence of synthetic fibers dispersed reinforced concrete," Applied Mechanics and Materials, vol. 725-726, pp. 543-558, 2015.

[13] T. Palanisamy and G. Dineshkumar, "Performance evaluation and structural behavior of basalt fiber reinforced concrete," International Journal of Earth Sciences and Engineering, vol. 7, no. 2, pp. 744-749, 2014.

[14] N. M. Morozov, I. Viktorovich Borovskich, and V. G. Khozin, "Sand bazalt-fiber concrete," World Applied Sciences Journal, vol. 25, no. 5, pp. 832-838, 2013.

[15] J. Wang, Y. Ma, Y. Zhang, and W. Chen, "Experimental research and analysis on mechanical properties of chopped Basalt fiber reinforced concrete," Engineering Mechanics, vol. 31, pp. 99-114, 2014. 
[16] C. H. Dong and X. W. Ma, "Experimental research on mechanical properties of basalt fiber reinforced reactive powder concrete," Advanced Materials Research, vol. 893, pp. 610-613, 2014.

[17] C. Jiang, K. Fan, F. Wu, and D. Chen, "Experimental study on the mechanical properties and microstructure of chopped basalt fibre reinforced concrete," Materials and Design, vol. 58, pp. 187193, 2014.

[18] N. Kabay, "Abrasion resistance and fracture energy of concretes with basalt fiber," Construction and Building Materials, vol. 50, pp. 95-101, 2014. 


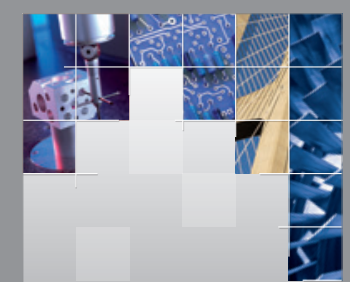

\section{Enfincering}
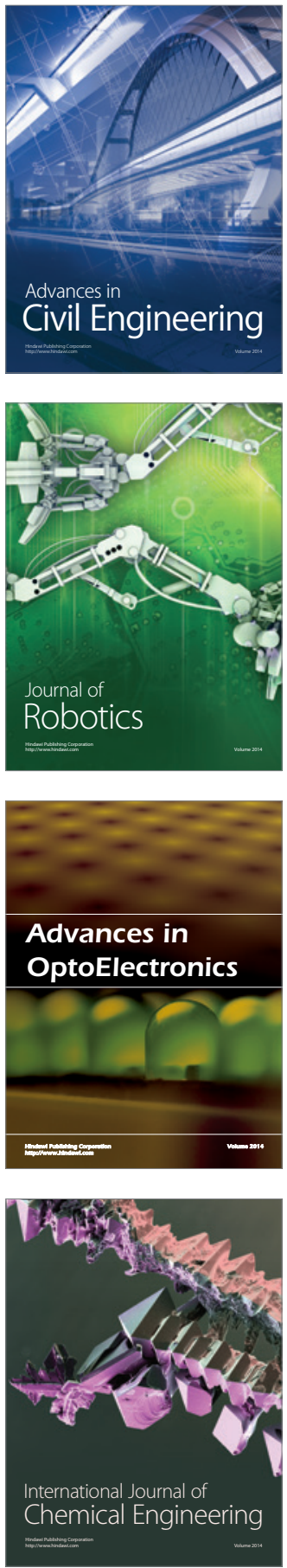

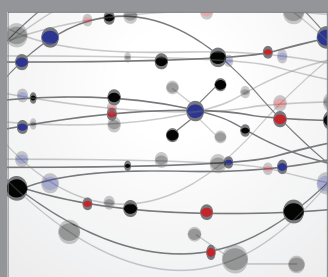

The Scientific World Journal

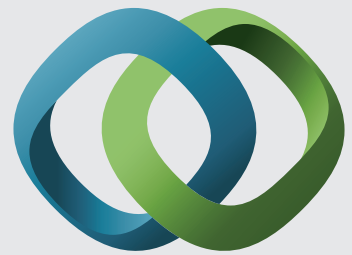

\section{Hindawi}

Submit your manuscripts at

http://www.hindawi.com
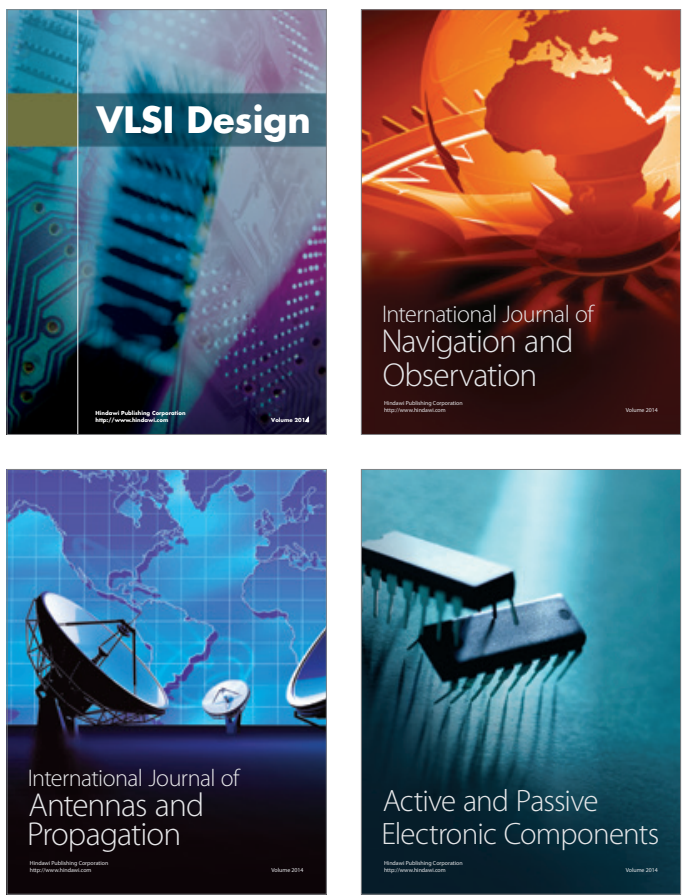
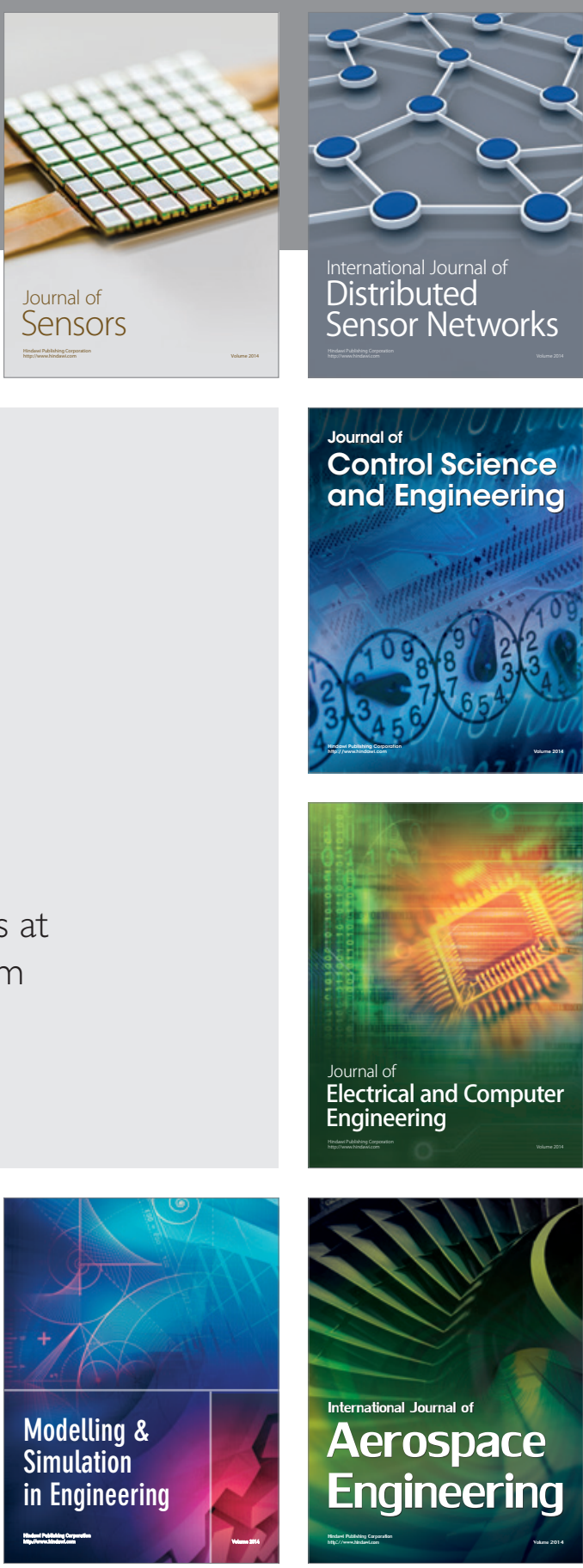

International Journal of

Distributed

Sensor Networks

Journal of

Control Science

and Engineering
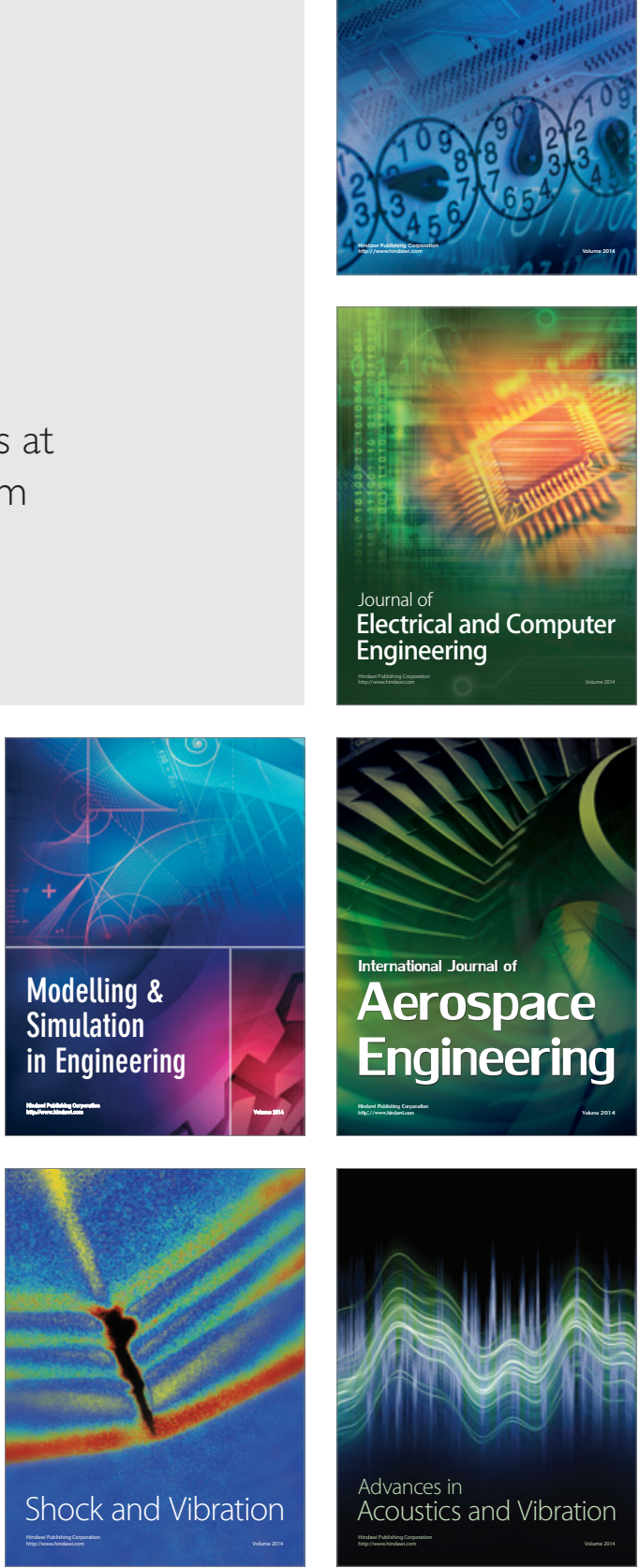